\title{
Association of malnutrition and low quality of life among cancer patients receiving chemotherapy, Palestine
}

\author{
Manal Badrasawi, ${ }^{1}$ Aseel Al-Adhame ${ }^{2}$ and Aseel Doufish ${ }^{2}$
}

${ }^{1}$ Nutrition and Food Technology Department, Faculty of Agriculture and Veterinary Medicine, An-Najah National University, Nablus, Palestine (Correspondence to: M. Badrasawi: manalpharmacist@gmail.com). ${ }^{2}$ Program of Therapeutic Nutrition, College of Medicine and Health Sciences, Palestine Polytechnic University, Hebron, Palestine.

\begin{abstract}
Background: Malnutrition is significantly associated with poor clinical outcomes and reduced quality of life among cancer patients. Although the number of cancer patients receiving chemotherapy has increased in Palestine, there has been limited research on the relationship between malnutrition and quality of life.

Aims: To determine the relationship between nutritional status and quality of life of cancer patients receiving chemotherapy at Al-Hussein Governmental Hospital in Biet-Jala, Palestine.

Methods: This cross-sectional study included all the patients receiving chemotherapy between 2018 and 2019. Nutritional status was assessed using anthropometric measurements and biochemical data retrieved from the participating patients' files. The clinical assessment of malnutrition was done using the Subjective Global Assessment, and quality of life was assessed using the European Organization for Research and Treatment of Cancer QLQ-C30 questionnaire version 3.

Results: One hundred patients (79 female, 21 male) were included in the final analysis. The results revealed that $25 \%$ of the patients were severely malnourished, and $42 \%$ were mildly to moderately malnourished. There was a significant relationship between malnutrition and quality of life in the following domains: physical functioning, cognitive functioning and fatigue.

Conclusions: Malnutrition is prevalent among Palestinian cancer patients receiving chemotherapy, and it is associated with poor quality of life. The results of the study highlight the need for nutritional support programmes for cancer patients to enhance their nutritional status and improve their quality of life.

Keywords: cancer patients, chemotherapy, nutritional status, quality of life, Palestine

Citation: Badrasawi M; Al-Adhame A; Doufish A. Association of malnutrition and low quality of life among cancer patients receiving chemotherapy, Palestine. East Mediterr Health J. 2021;27(5):459-466. https://doi.org/10.26719/2021.27.5.459

Received: 29/10/19; accepted: 19/05/20

Copyright (c) World Health Organization (WHO) 2021. Open Access. Some rights reserved. This work is available under the CC BY-NC-SA 3.o IGO license (https://creativecommons.org/licenses/by-nc-sa/3.o/igo)
\end{abstract}

\section{Introduction}

Cancer is the second leading cause of death worldwide. The global cancer burden had risen to 18.1 million new cases and 9.6 million deaths in 2018. Recent statistics have reported that 1 in 5 men and 1 in 6 women worldwide develop cancer during their lifetime, and one in 8 men and one in 11 women die from cancer (1). In Palestine, cancer is increasingly becoming a public health concern and it is the second most common cause of death. A total of 2536 new cases of cancer were reported in the West Bank in 2016.

Malnutrition is a common problem among cancer patients due to the cancer itself and the adverse effects of cancer treatment (2). The prevalence and severity of malnutrition depend on the tumour stage and site (3). Chemotherapy is aggressive and negatively affects the physical and psychological status of cancer patients, and it has serious adverse effects on their nutritional status $(4,5)$. Moreover, cancer patients undergoing chemotherapy often experience taste and smell changes which affect their dietary intake (6). For these reasons, all cancer patients should be screened regularly for the risk or presence of malnutrition, and to consider nutritional support as a part of the cancer management plan (7). Prevalence of malnutrition varies among countries. For example, in a study conducted in Japan, the prevalence of malnutrition among 152 cancer patients was 19\%. In Italy, malnutrition was 9\% while nutritional impairment was $51 \%$ among 1950 cancer patients in 22 medical centres (8). Among 822 Irish cancer patients, 36\% reported body weight loss $>5 \%$ (9).

Quality of life (QOL) is an essential aspect of the medical treatment plans involving patients with chronic diseases, and it is considered a clinical measure of health care (10). However, for cancer patients, adverse effects of chemotherapy have a strong impact on QOL (11). The factors that negatively affect QOL of cancer patients are fatigue, anxiety, functional impairments and body image (12).

There is a known relationship between malnutrition and poor QOL in cancer patients (13). Malnourished patients feel weak and tend to stop their usual activities, which, in turn, adversely affects their QOL (14). Chemotherapy-associated weight loss leads to poor physical and social functioning, while weight gain with some treatment regimens is associated with adverse 
effects on emotional and social functions (15). It can be inferred that cancer patients with good nutritional status have better QOL during chemotherapy as compared to malnourished patients. Hence, QOL should be regarded as a primary outcome measure for nutritional interventions among cancer patients.

This research aimed to determine the prevalence of malnutrition among Palestinian cancer patients and its relationship with QOL. There is a need for this type of research as the number of cancer cases has been increasing in Palestine.

\section{Methods}

This cross-sectional study was conducted at Al-Hussein Governmental Hospital in Biet Jala, West Bank, Palestine. Data collection was conducted through interviews with patients and clinical assessments, and the hospital database provided the cancer patients' profiles and biochemical data. Initially, $>150$ patients from the Oncology Day Care Unit were invited to participate. This unit treats patients receiving chemotherapy. Patients who did not consent to the study or refused to continue with the full assessment were excluded. A total of 100 patients were included in the final analysis. The inclusion criteria were patients aged $\geq 18$ years who were receiving chemotherapy at Al-Hussein Governmental Hospital from October 2018 to March 2019. The exclusion criteria were: age $\leq$ 18 years, mental disabilities, and admission to hospital wards or intensive care units.

The Deanship of Scientific Research in the Palestine Polytechnic University gave ethical approval (Ref no. $\mathrm{KA} / 41 / 2018$ ) for the research protocol. The Palestinian Ministry of Health granted permission to collect the required data. Written consent forms were obtained from the patients after they had been briefed about the purpose of the study.

QOL was assessed using the validated Arabic version of the European Organization for Research and Treatment of Cancer (EORTC) C-30 version 3.0 questionnaire. EORTC C-30 is a widely used and accepted tool to assess QOL of cancer patients. The EORTC C-30 psychometric properties have been examined across cultural samples in 13 countries (16). The Arabic version of EORTC-C 30 was validated in neighbouring Lebanon (17). The scoring of each item and the total items was according to the steps reported in the EORTC-C30 manual (18). The reliability of the tool was assessed using Cronbach $\alpha$ coefficient with a value of 0.863 .

The Subjective Global Assessment (SGA) tool was used to determine the nutritional status of the participants. SGA is a valid tool widely used to diagnose malnutrition among cancer patients (19). It consists of 2 main sections: nutritional medical history and physical examination for subcutaneous fat and muscle. The nutritional medical history includes weight changes (during the last 6 months and last 2 weeks); dietary intake changes and adequacy; gastrointestinal symptoms (like nausea, vomiting, diarrhoea and anorexia for the last 2 weeks); and functional capacity (if there is any dysfunction or mobility difficulties, and the duration of these difficulties). The physical examination includes clinical assessment for subcutaneous fat (under the eyes, triceps and biceps) and muscle wasting (in the temple, clavicle, shoulder, scapula/ ribs, quadriceps, calf, knee and interosseous muscle between thumb and forefinger), in addition to observation for oedema or ascites. The patients were classified into well-nourished (Category A), moderately malnourished Category B) or severely malnourished (Category C). Well-trained dietitians conducted all the assessments.

Nutritional biochemical assessment using laboratory tests was done on the patients. The relevant data from the hospital databases for each patient were extracted including albumin, complete blood count, creatinine, and blood urea nitrogen. These tests were routine laboratory tests according to the hospital protocols. Data related to cancer stage, location, treatment plan and number of chemotherapy sessions were also extracted from the patients' files.

SPSS version 21 was used for data entry and analysis. Descriptive statistics (frequencies, percentages, means and standard deviations) were carried out. The $\chi^{2}$ test was performed to determine the association between malnutrition and the independent categorical variables, while the independent samplest test and one-way analysis of variance were used to determine the mean differences for selected variables. $P<0.05$ was considered significant.

\section{Results}

\section{Participants' characteristics}

Participants' characteristics are presented in Table 1. The mean age of the participants was 52 (11) years, ranging from 22 to 80 years, with a significant difference between men [61 (15) years] and women [51 (10) years] $(P<$ 0.01 using independent samples $t$ test).

The medical history of the participants revealed considerable comorbidity: $20 \%$ of the participants had diabetes, $25 \%$ hypertension, $8 \%$ dyslipidaemia, $3 \%$ history of heart diseases, and $62 \%$ reported previous operations other than for cancer treatment.

For cancer staging, the patients' files showed $32 \%$ of the patients with stage III, $29 \%$ stage II, $24 \%$ stage 1 and $15 \%$ stage IV, with no significant difference between men and women. Metastasis was reported in $11 \%$ of patients. Patients with breast cancer formed the majority of the study sample $(49 \%)$, followed by colon cancer $10 \%$, lymphoma $9 \%$, prostate cancer $4 \%$, and leukaemia $3 \%$. Other cancers were reported to be $<2 \%$ (liver, bone, pancreas, stomach and bone cancer). For cancer treatment, $34 \%$ of the patients underwent surgery before starting chemotherapy, and 20\% received radiotherapy during their treatment plan. In terms of the number of chemotherapy sessions, $16 \%$ of the patients had $2-5$ sessions, 50\% had 6-10, while the rest had $>10$. 


\begin{tabular}{lccc}
\hline Table 1 Participant characteristics & & \\
\hline $\begin{array}{l}\text { Demographic } \\
\text { characteristics }\end{array}$ & Value & No. & $\%$ \\
\hline Sex & Male & 21 & 21 \\
& Female & 79 & 79 \\
Personal status & Married & 92 & 92 \\
& Single & 7 & 7 \\
& Divorced & 1 & 1 \\
Education & Primary & 46 & 46 \\
& Secondary & 30 & 30 \\
& Diploma & 11 & 11 \\
Area of living & Postgraduate & 13 & 13 \\
& Hebron & 67 & 67 \\
& Bethlehem & 13 & 13 \\
& Ramallah & 18 & 18 \\
& Jericho & 1 & 1 \\
Work & Jerusalem & 1 & 1 \\
& Works & 18 & 18 \\
& Does not work & 73 & 73 \\
Smoking & Retired & 9 & 9 \\
& Smoker & 13 & 13 \\
& Non-smoker & 83 & 83 \\
& Ex-smoker & 4 & 4 \\
\hline
\end{tabular}

The patients' nutritional assessment according to SGA showed that $33 \%$ of the participants were well-nourished, $42 \%$ mildly to moderately malnourished, and $25 \%$ severely malnourished, with no significant differences between men and women. There was a significant association between cancer stage and nutritional status: stages 3 and 4 were associated with severe malnourishment compared with stages 1 and $2\left(P<0.05, \chi^{2}\right.$ test). The nutritional status of the participants according to SGA domains is presented in Figure 1. Severe weight loss (> 10\% of body weight) was reported among $31 \%$ of the patients, inadequate dietary intake was reported in $22 \%$, and $58 \%$ reported limitation in the functional status and mobility. Loss of subcutaneous fat around the eyes, triceps and biceps was $8 \%, 39 \%$ and $38 \%$, respectively. Moderate and severe muscle wasting differed according to the muscle sites. The biochemical data showed that $24 \%$ of the participants had low haemoglobin level, and $27 \%$ and $20 \%$ had low numbers of red blood cells and white blood cells, respectively; $14 \%$ had low albumin level; and $7 \%$ had high creatinine and blood urea nitrogen levels.

The relationship between nutritional status and QOL is presented in Table 2. Significantly lower functional status was found among severely malnourished patients compared with well-nourished and mild-to-moderately malnourished patients $(P<0.05)$. Severely malnourished patients reported significantly higher fatigue score compared with well-nourished and mild-to-moderately malnourished patients $(P<0.05)$.

The relationship between cancer stage and QOL is presented in Table 3. There was a significantly poor score in most of the 3 QOL domains in patients with advanced cancer $(P<0.05)$, except for dyspnoea, diarrhoea, financial difficulties, social functioning, nausea, and vomiting.

\section{Discussion}

This study successfully determined the prevalence of malnutrition $(25 \%)$ and the risk of malnutrition $(42 \%)$ among cancer patients during chemotherapy treatment. The prevalence of malnutrition was higher among those with advanced cancer stages. With regard to QOL, malnourished patients had lower functional status and higher fatigue level compared with well-nourished and mildly nourished patients. One hundred patients (79 female and 21 male) were included in the present study. The biochemical data were extracted from the patients' files. Only 44 patients had their albumin measured because this was only indicated in types of cancer with high catabolism, and not for all patients receiving chemotherapy according to the hospital follow-up.

Clinical assessment of the nutritional status revealed that $42 \%$ had mild-to-moderate malnutrition (SGA Category B), and $25 \%$ were severely malnourished (SGA Category C).This result is consistent with previous studies. For instance, Vergara et al. reported that $40.2 \%$ of cancer patients receiving chemotherapy were malnourished, using SGA scoring (20). In a large multicentre study in China, of 23218 cancer patients receiving chemotherapy, $31.3 \%$ were moderately malnourished and $26.5 \%$ were severely malnourished using the Patients Generated Subjective Global Assessment (SGA) to diagnose malnutrition (21). In the Republic of Korea, the prevalence of malnutrition using SGA ranged from $19.8 \%$ to $34.5 \%$ depending on cancer treatment (22). The considerable prevalence of malnutrition among cancer patients is explained by the metabolic stress levels due to cancer and the adverse effects of treatment, which decreases dietary intake and leads to loss in weight and functional reserve (20).

The relationship between QOL and nutritional status was significant in certain domains of QOL: physical function, cognitive function and fatigue. Malnourished patients scored less for physical and cognitive functions, and scored more for fatigue. Generally, cancer patients' QOL scores are low $(23,24)$. The QOL domains of overall health, physical function and fatigue were highly prevalent among cancer patients with nutritional problems (24). Much research has reported that malnutrition adversely affects QOL among cancer patients receiving chemotherapy (25-28). Moreover, malnutrition adversely affects patients' survival (9). In a cross-sectional study conducted among $>1000$ cancer patients, malnutrition was a significant predictor for poor QOL (25). There is a significant relationship between pain from cancer treatment and metabolic changes due to cancer (26). Malnutrition, theoretically and clinically, is associated with low QOL among cancer patients during chemotherapy. Based on these findings, enhancing the nutritional status for cancer patients could improve the clinical outcomes and QOL (28).

The results of the current study revealed that patients with advanced stage 3 and 4 cancer reported lower QOL compared with patients with stages 1 and 2 cancer. The 
Figure 1 Patients' nutritional status according to Subjective Global Assessment Domain

100

(A) Percentage of weight loss over the last 6 months

80

$\%$

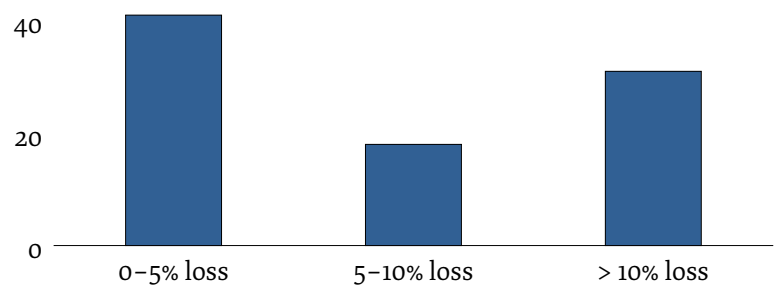

60

$0-5 \%$ loss
(C) Changes in dietary intake for the last 2 weeks
100

80

60

$\%$

40

20

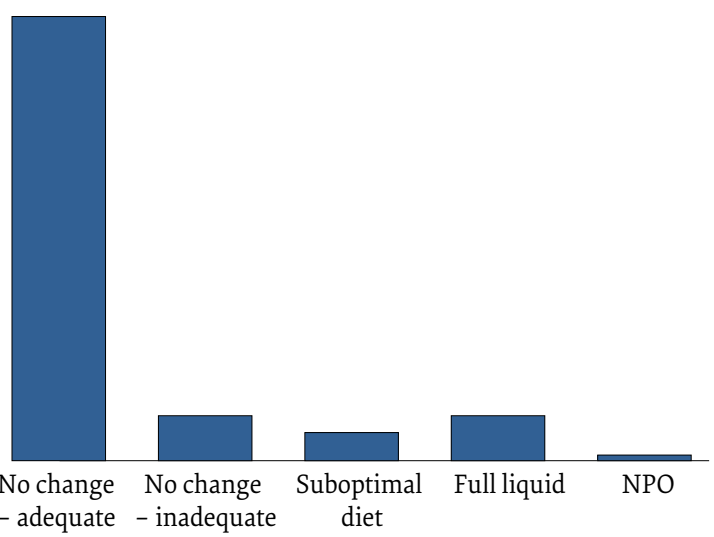

(B) Presence of gastrointestinal symptoms

100

80

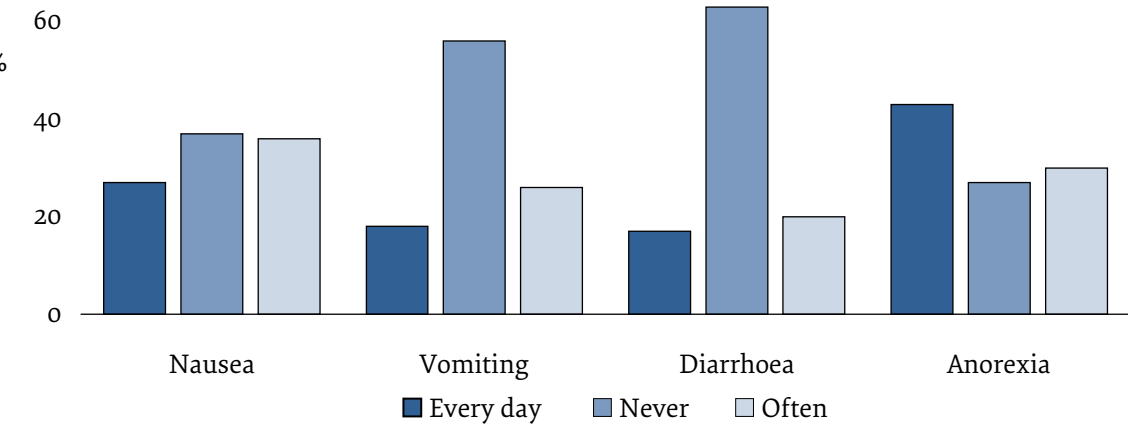

(D) Changes in functional status

100

80

60

$\%$

40

20

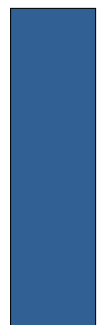

o No dysfunction Difficulty with Bed/chair-ridden ambulation/normal

$$
\text { activity }
$$

100

(E) Percentage of subcutaneous fat loss

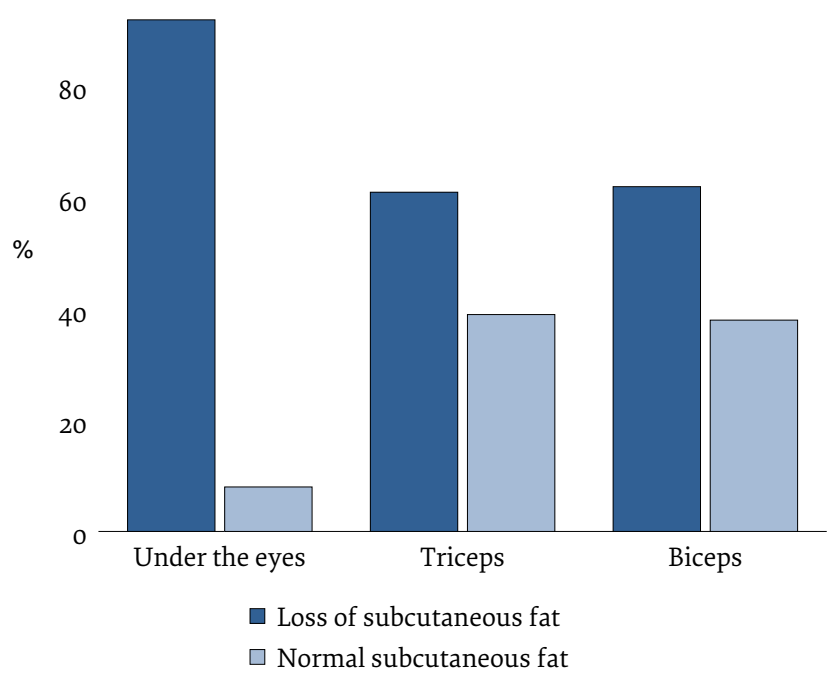


100

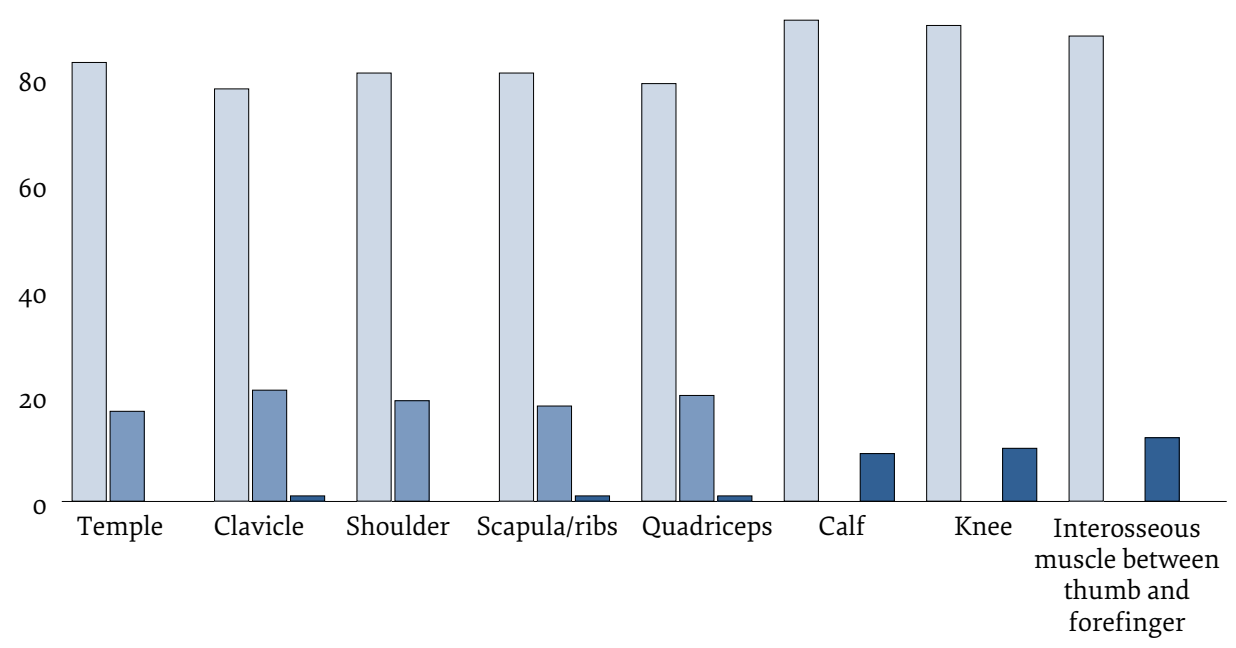

Severe muscle wasting relationship was significant for pain, insomnia and constipation. Patients with stages 3 and 4 cancer scored lower in the global health status domain, and stage 4 cancer patients reported significantly lower scores compared with patients with other stages of cancer. Similarly, the physical, emotional, role functioning and cognitive functions were significantly lower for patients with advanced cancer stages. The incidence of fatigue was significantly higher in stage 4 than in other stages. These findings confirmed the relationship between cancer stage and QOL. Al Zahrani et al. found a significantly lower QOL for advanced cancer stages among women with breast cancer from Saudi Arabia (29). This can be explained by the fact that the severity of cancer symptoms increases with advanced stages, and QOL is determined by severity of disease symptoms. Severe symptoms hinder patients' social roles, with increased levels of irritation, distress and depression, especially in advanced cancer stages (10). Malnutrition is also a contributing factor to low QOL. It is well documented that nutritional problems and

\begin{tabular}{|c|c|c|c|c|}
\hline & $\begin{array}{l}\text { Well-nourished } \\
\qquad(\mathbf{n}=33)\end{array}$ & $\begin{array}{l}\text { Mildly/moderately malnourished } \\
\qquad(\mathrm{n}=42)\end{array}$ & $\begin{array}{l}\text { Severely malnourished } \\
\qquad(\mathrm{n}=25)\end{array}$ & $\boldsymbol{P}$ \\
\hline Pain & $18.1(20.1)$ & $17.8(21.5)$ & $26.6(29.2)$ & 0.277 \\
\hline Dyspnoea & $20.2(28.7)$ & $11.1(21.6)$ & $12(25.2)$ & 0.262 \\
\hline Insomnia & $44.4(39.6)$ & $40.4(42.6)$ & $58.6(40)$ & 0.209 \\
\hline Appetite loss & $29.2(34.1)$ & $37.3(28.7)$ & $46.6(37.2)$ & 0.141 \\
\hline Constipation & $13.1(21.9)$ & $19(27.6)$ & $21.3(28.6)$ & 0.453 \\
\hline Diarrhoea & $11.1(23)$ & $14.2(26.6)$ & $21.3(33.1)$ & 0.365 \\
\hline Financial difficulties & $13.1(23.4)$ & $15(26.7)$ & $9.3(26.3)$ & 0.675 \\
\hline Global health status & $69.4(16.7)$ & $65(15)$ & $59(16.8)$ & 0.055 \\
\hline Physical functioning & $65.8(20.4)$ & $72.3(17.6)$ & $58.6(25.6)$ & 0.035 \\
\hline Role functioning & $83.3(23.1)$ & $88.8(19.7)$ & $83.3(29.2)$ & 0.510 \\
\hline Emotional function & $63.3(28.5)$ & $71.2(30.5)$ & $59.3(33.4)$ & 0.273 \\
\hline Cognitive functioning & $70.7(29.1)$ & $86.5(19.9)$ & $66(25.6)$ & 0.002 \\
\hline Social functioning & $87.3(19.5)$ & $80.1(25)$ & $82.6(20.1)$ & 0.376 \\
\hline Fatigue & $38.3(27)$ & $35.9(26.8)$ & $54.2(27.2)$ & 0.024 \\
\hline Nausea, vomiting & $18.6(24.9)$ & $20.2(21.6)$ & $18.6(22.2)$ & 0.945 \\
\hline
\end{tabular}

Results presented as mean (standard deviation). SGA = Subjective Global Assessment. 


\begin{tabular}{|c|c|c|c|c|c|}
\hline & Stage 1 & Stage 2 & Stage 3 & Stage 4 & $P$ \\
\hline Pain & $14.5(22.1)$ & $10.9(15.6)$ & $26(21.9)$ & $34.4(31.1)$ & 0.003 \\
\hline Dyspnoea & $15.2(29.4)$ & $10.3(23.7)$ & $15.6(22.3)$ & $17.7(27.7)$ & 0.776 \\
\hline Insomnia & $34.7(38.6)$ & $42.5(38.7)$ & $42.7(41.6)$ & $80(35.1)$ & 0.005 \\
\hline Appetite loss & $26.3(31)$ & $41.3(34.1)$ & $33.3(32.7)$ & $53.3(30.3)$ & 0.069 \\
\hline Constipation & $18(31)$ & $20.6(27.3)$ & $8.3(14.6)$ & $31.1(29.4)$ & 0.035 \\
\hline Diarrhoea & $9.7(20.8)$ & $17.2(29)$ & $17.7(29.3)$ & $13.3(30.3)$ & 0.699 \\
\hline Financial difficulties & $15.2(27.7)$ & $12.6(25.8)$ & $12.5(21.9)$ & $11.1(29.9)$ & 0.963 \\
\hline Global health status & $68(15)$ & $67.8(14.8)$ & $66.9(15.4)$ & $50.5(17)$ & 0.002 \\
\hline Physical functioning & $68(22.9)$ & $77.7(16.7)$ & $62.9(19)$ & $52(21.4)$ & 0.001 \\
\hline Role functioning & $90.2(19.6)$ & $91.3(19.2)$ & $83.3(23.1)$ & $72.2(31.9)$ & 0.046 \\
\hline Emotional functioning & $58.3(31.5)$ & $74.4(29.3)$ & $73.1(26.8)$ & $44.4(29.6)$ & 0.004 \\
\hline Cognitive functioning & $81.2(24.2)$ & $79.8(22.4)$ & $77.6(26.6)$ & $57.7(28.7)$ & 0.026 \\
\hline Social functioning & $84(21.6)$ & $85.6(22.5)$ & $83.8(19.1)$ & $75.5(28)$ & 0.539 \\
\hline Fatigue & $37.5(25.5)$ & $31.4(27.5)$ & $44(28)$ & $60.7(22.1)$ & 0.007 \\
\hline Nausea, vomiting & $17.3(21.6)$ & $24.7(23.8)$ & $14.5(21.4)$ & $22.2(24.1)$ & 0.330 \\
\hline
\end{tabular}

Results presented as mean (standard deviation).

malnutrition increase with advanced cancer stages (30); therefore, lower QOL scores among patients with stage 4 compared with stages 1 and 2 are to be expected (10).

This study had some limitations. The study was conducted in a single medical centre on a small sample. The inclusion criteria included different types and stages of cancer. The study design was cross-sectional, which only defined the relationship between QOL and malnutrition without determination of the cause and effect relationship.

\section{Conclusions}

The results revealed that $25 \%$ of the patients were severely malnourished and $42 \%$ were mildly to moderately malnourished. A significant association was found between cancer stage and nutritional status, with higher stages associated more with being severely malnourished. Sig- nificantly lower functional status, higher fatigue levels and lower QOL scores were found among severely malnourished cancer patients compared with well-nourished and mildly to moderately malnourished patients. The results highlight the need for routine nutritional assessment of all patients referred for chemotherapy. Likewise, the study provides evidence of the importance of early nutritional intervention programmes for cancer patients receiving chemotherapy to enhance their nutritional status and improve their QOL. Further research is needed to determine the cause and effect relationship between malnutrition and QOL in longitudinal prospective design. Furthermore, intervention studies are needed to optimize the nutritional intervention protocol among Palestinian cancer patients receiving chemotherapy.

\section{Funding: None.}

Competing interests: None declared.

\section{Association de la malnutrition et de la mauvaise qualité de vie chez les patients cancéreux sous chimiothérapie, Palestine}

\section{Résumé}

Contexte : La malnutrition est associée de manière significative à de mauvais résultats cliniques et à une qualité de vie réduite chez les patients cancéreux. Bien que le nombre de patients cancéreux sous chimiothérapie ait augmenté en Palestine, les recherches sur le lien entre malnutrition et qualité de vie ont été limitées.

Objectifs : Déterminer la relation entre l'état nutritionnel et la qualité de vie des patients cancéreux recevant une chimiothérapie à l'hôpital public Al-Hussein de Biet-Jala, en Palestine.

Méthodes: La présente étude transversale incluait tous les patients sous chimiothérapie entre 2018 et 2019. L'état nutritionnel a été évalué à l'aide de mesures anthropométriques et de données biochimiques tirées des dossiers des patients participant. L'évaluation clinique de la malnutrition a été réalisée à l'aide de l'évaluation globale subjective, et la qualité de vie a été déterminée à l'aide de la version 3 du questionnaire QLQ-C30 de l'Organisation européenne pour la recherche et le traitement du cancer.

Résultats : Cent patients (79 femmes, 21 hommes) ont été inclus dans l'analyse finale. Les résultats ont révélé que $25 \%$ des patients souffraient de malnutrition sévère, et $42 \%$ de malnutrition légère à modérée. Il existait une relation 
significative entre la malnutrition et la qualité de vie dans les domaines suivants : le fonctionnement physique, le fonctionnement cognitif et la fatigue.

Conclusions: La malnutrition est prévalente chez les patients palestiniens atteints de cancer et elle est associée à une mauvaise qualité de vie. Les résultats de l'étude soulignent la nécessité de programmes de soutien nutritionnel pour les patients atteints de cancer afin d'améliorer leur état nutritionnel et leur qualité de vie.

$$
\begin{aligned}
& \text { الارتباط بين سوء التغذية وانخفاض جودة الحياة في صفوف مرضى السرطان الذين يتلقون معالجة كيميائية، فلسطين }
\end{aligned}
$$

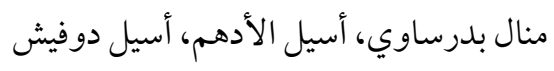

$$
\begin{aligned}
& \text { الخلاصة }
\end{aligned}
$$

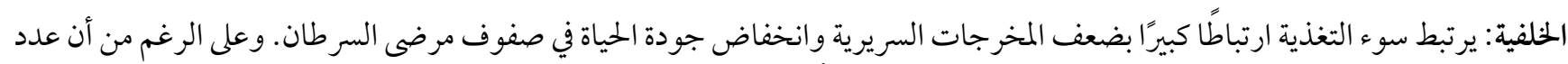

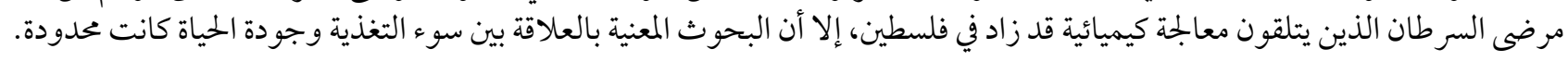

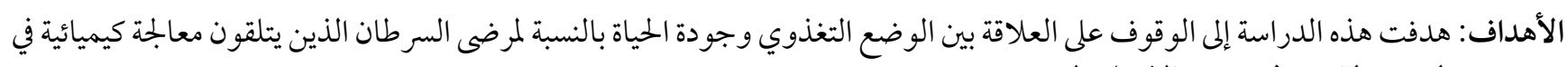

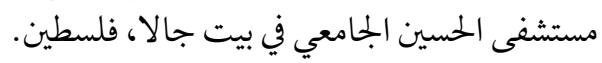

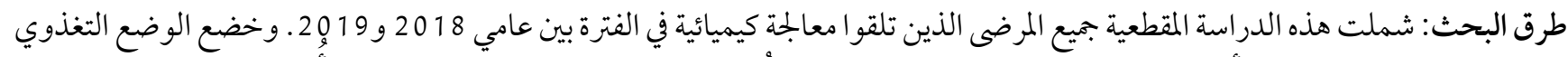

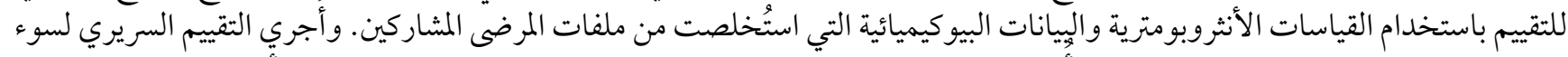

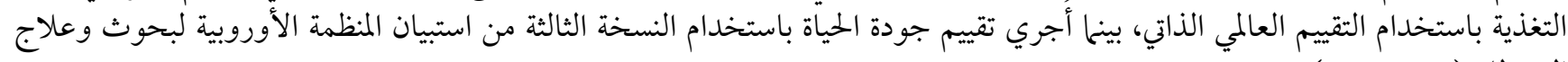

$$
\begin{aligned}
& \text { السرطان (QLQ-C30). }
\end{aligned}
$$

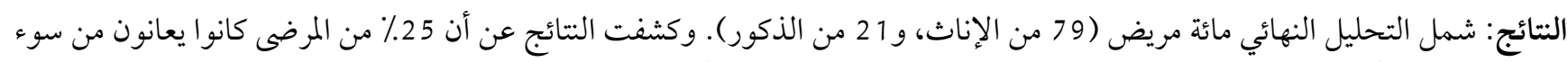

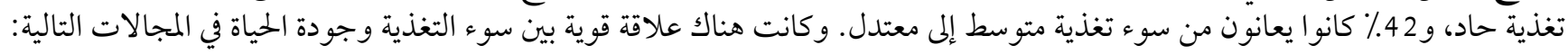

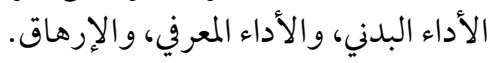

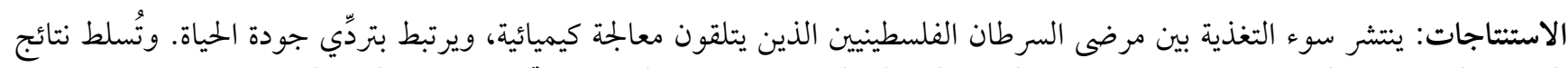

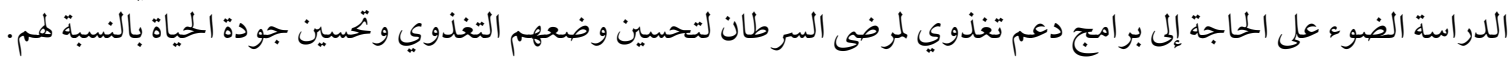

\section{References}

1. Bray F, Ferlay J, Soerjomataram I, Siegel RL, Torre LA, Jemal A. Global cancer statistics 2018: GLOBOCAN estimates of incidence and mortality worldwide for 36 cancers in 185 countries. CA Cancer J Clin. 2018 Nov;68(6):394-424. https://doi.org/10.3322/caac.21492 PMID:30207593

2. Seo SH, Kim S-E, Kang Y-K, Ryoo B-Y, Ryu M-H, Jeong JH, et al. Association of nutritional status-related indices and chemotherapy-induced adverse events in gastric cancer patients. BMC cancer. 2016 Nov 18;16(1):900. https://doi.org/10.1186/s12885-016-2934-5 PMID:27863481

3. Caccialanza R, De Lorenzo F, Gianotti L, Zagonel V, Gavazzi C, Farina G, et al. Nutritional support for cancer patients: still a neglected right? Supportive Care Cancer. 2017 Oct;25(10):3001-4. https://doi.org/10.1007/soo520-017-3826-1 PMID:28710645

4. Salas S, Mercier S, Moheng B, Olivet S, Garcia M-E, Hamon S, et al. Nutritional status and quality of life of cancer patients needing exclusive chemotherapy: a longitudinal study. Health and quality of life outcomes. 2017 Apr 27;15(1):85. https://doi.org/10.1186/s12955-017-0660-6 PMID:28449674

5. Wagland R, Richardson A, Armes J, Hankins M, Lennan E, Griffiths P. Treatment-related problems experienced by cancer patients undergoing chemotherapy: a scoping review. Eur J Cancer Care. 2015 Sep;24(5):605-17. https://doi.org/10.1111/ecc.12246 PMID:25296389

6. IJpma I, Renken RJ, Ter Horst GJ, Reyners AK. The palatability of oral nutritional supplements: before, during, and after chemotherapy. Supportive Care Cancer. 2016 Oct;24(10):4301-8. https://doi.org/10.1007/s00520-016-3263-6 PMID:27220522

7. Arends J, Bachmann P, Baracos V, Barthelemy N, Bertz H, Bozzetti F, et al. ESPEN guidelines on nutrition in cancer patients. Clin Nutr. 2017 Feb;36(1):11-48. https://doi.org/10.1016/j.clnu.2016.07.015 PMID:27637832

8. Muscaritoli M, Lucia S, Farcomeni A, Lorusso V, Saracino V, Barone C, et al. Prevalence of malnutrition in patients at first medical oncology visit: the PreMiO study. Oncotarget. 2017 Aug 10;8(45):79884-96. https://doi.org/10.18632/oncotarget.20168 PMID:29108370

9. Daly L, Bhuachalla ÉN, Cushen S, Power D, O'Reilly S, McEneaney P, et al. Malnutrition in 822 Irish cancer patients undergoing chemotherapy: prevalence and impact on quality of life and survival. Annals of Oncology. 2016 Oct 1;27(Suppl 6):VI501. https:// doi.org/10.1093/annonc/mdw390.15 
10. Polanski J, Jankowska-Polanska B, Rosinczuk J, Chabowski M, Szymanska-Chabowska A. Quality of life of patients with lung cancer. Onco Targets Ther. 2016 Feb 29;9:1023.https://doi.org/10.2147/OTT.S100685 PMID:27013895

11. Lorusso D, Bria E, Costantini A, Di Maio M, Rosti G, Mancuso A. Patients' perception of chemotherapy side effects: expectations, doctor-patient communication and impact on quality of life - an Italian survey. Eur J Cancer Care. 2017 Mar;26(2):e12618. https:// doi.org/10.1111/ecc.12618 PMID:28004440

12. Üstündağ S, Zencirci AD. Factors affecting the quality of life of cancer patients undergoing chemotherapy: a questionnaire study. Asia Pac J Oncol Nurs. 2015 Jan-Mar;2(1):17-25. https://doi.org/10.4103/2347-5625.152402 PMID:27981088

13. Jager-Wittenaar H, Ottery FD. Assessing nutritional status in cancer: role of the Patient-Generated Subjective Global Assessment. Curr Opin Clin Nutr Metab Care. 2017 Sep;20(5):322-9. https://doi.org/10.1097/MCO.0000000000000389 PMID:28562490

14. Gellrich N-C, Handschel J, Holtmann H, Krüskemper G. Oral cancer malnutrition impacts weight and quality of life. Nutrients. 2015 Mar 27;7(4):2145-60. https://doi.org/10.3390/nu7042145 PMID:25825828

15. Brinksma A, Sanderman R, Roodbol PF, Sulkers E, Burgerhof JG, de Bont ES, et al. Malnutrition is associated with worse health-related quality of life in children with cancer. Supportive Care Cancer. 2015 Oct;23(10):3043-52. https://doi.org/10.1007/ s00520-015-2674-o PMID:25752883

16. Aaronson NK, Ahmedzai S, Bergman B, Bullinger M, Cull A, Duez NJ, et al. The European Organization for Research and Treatment of Cancer QLQ-C30: a quality-of-life instrument for use in international clinical trials in oncology. J Natl Cancer Inst. 1993 Mar 3;85(5):365-76. https://doi.org/10.1093/jnci/85.5.365 PMID:8433390

17. Huijer HA-S, Sagherian K, Tamim H. Validation of the Arabic version of the EORTC quality of life questionnaire among cancer patients in Lebanon. Qual Life Res. 2013 Aug;22(6):1473-81. https://doi.org/10.1007/s11136-012-0261-o PMID:22961075

18. Scott NW, Fayers P, Aaronson NK, Bottomley A, de Graeff A, Groenvold M, et al. EORTC QLQ-C30 reference values manual. Brussels: European Organisation for Research and Treatment of Cancer; 2008 (https://www.eortc.org/app/uploads/sites/2/2018/02/ reference_values_manual2008.pdf, accessed 19 December 2020).

19. Thoresen L, Fjeldstad I, Krogstad K, Kaasa S, Falkmer UG. Nutritional status of patients with advanced cancer: the value of using the subjective global assessment of nutritional status as a screening tool. Palliat Med. 2002 Jan;16(1):33-42. https://doi.org/10.1191/0269216302pm486oa PMID:11963449

20. Vergara N, Montoya JE, Luna HG, Amparo JR, Cristal-Luna G. Quality of life and nutritional status among cancer patients on chemotherapy. Oman Med J. 2013 Jul;28(4):270. https://doi.org/10.5001/omj.2013.75 PMID:23904921

21. Xu H, Shi H, Li W. MON-LB268: Malnutrition and Quality of Life In Patients with Cancer in China: a clinical study with 23,618 subjects. Clin Nutr. 2016 Sep 1;35(Suppl 1):S251-2. https://doi.org/10.1016/So261-5614(16)30902-5

22. Lim H-S, Cho G-S, Park Y-H, Kim S-K. Comparison of quality of life and nutritional status in gastric cancer patients undergoing gastrectomies. Clin Nutr Res. 2015 Jul;4(3):153-9. https://doi.org/10.7762/cnr.2015.4.3.153 PMID:26251833

23. Thweib N. Quality of life of Palestinian cancer patients. J Pediatr Hematol Oncol. 2011 Apr;33(Suppl 1):S68-9. https://doi.org/10.1097/MPH.obo13e3182122438 PMID:21448042

24. Galindo DEB, Vidal-Casariego A, Calleja-Fernández A, Hernández-Moreno A, de la Maza BP, Pedraza-Lorenzo M, et al. Appetite disorders in cancer patients: impact on nutritional status and quality of life. Appetite. 2017 Jul 1;114:23-7. https://doi.org/10.1016/j.appet.2017.03.020 PMID:28315777

25. Sullivan E, Bhuachalla EN, Cushen S, Power D, Ryan A, Daly L. Malnutrition and body composition predict poor quality of life and reduced survival in ambulatory oncology patients receiving chemotherapy: a cross sectional study of 1015 patients. Proc Nutr Soc. 2018;77(OCE1):E5. https://doi.org/10.1017/So029665117004244

26. Alkan ŞB, Artac M, Rakıcıoglu N. The evaluation of relationship between malnutrition, quality of life and depression in cancer patients treated with chemotherapy. Clin Exp Health Sci. 2018;8(4):237-44.

27. Power DG, Cushen S, O'Reilly S, Ni Bhuachalla E, Mceneaney P, Daly L, et al. A prospective investigation of nutritional status in 517 Irish cancer patients undergoing chemotherapy: prevalence of malnutrition, cachexia, sarcopenia and impact on quality of life. Am Soc Clin Oncol. 2015;33(No. 15 Suppl). https://doi.org/10.1200/jco.2015.33.15_suppl.e20629

28. Zaid ZA, Jackson K, Cobiac L, Kandiah M. Relationship between quality of life and nutritional status in colorectal cancer patients undergoing chemotherapy. Malay J Nutr. 2017;23(3):375-84.

29. Al Zahrani AM, Alalawi Y, Yagoub U, Saud N, Siddig K. Quality of life of women with breast cancer undergoing treatment and follow-up at King Salman Armed Forces Hospital in Tabuk, Saudi Arabia. Breast Cancer. 2019 May 27;11:199-208. https://doi. org/10.2147/BCTT.S200605. eCollection 2019 PMID:31213890

30. Arends J, Baracos V, Bertz H, Bozzetti F, Calder P, Deutz N, et al. ESPEN expert group recommendations for action against cancer-related malnutrition. Clinical Nutrition. 2017 Oct;36(5):1187-96. https://doi.org/10.1016/j.clnu.2017.06.017 PMID:28689670 